\title{
Effect of Processing Methods on the Quality of Tomato Products
}

\author{
Qin Xu1 ${ }^{1 *}$, Irma Adyatni', Bradly Reuhs ${ }^{2}$ \\ ${ }^{1}$ Department of Food Science, School of Agriculture, Purdue University, West Lafayette, IN, USA \\ ${ }^{2}$ Whistler Center for Carbohydrate Research, Department of Food Science, School of Agriculture, Purdue University, West \\ Lafayette, IN, USA \\ Email: *xuq@purdue.edu
}

How to cite this paper: Xu, Q., Adyatni, I. and Reuhs, B. (2018) Effect of Processing Methods on the Quality of Tomato Products. Food and Nutrition Sciences, 9, 86-98. https://doi.org/10.4236/fns.2018.92007

Received: December 31, 2017

Accepted: February 11, 2018

Published: February 14, 2018

Copyright ( 92018 by authors and Scientific Research Publishing Inc. This work is licensed under the Creative Commons Attribution International License (CC BY 4.0).

http://creativecommons.org/licenses/by/4.0/

\section{(c) (i) Open Access}

\begin{abstract}
Tomatoes are one of the most important specialty crops in United States and tomato products constitute a significant part of the food industry. The quality of tomato paste and juice is evaluated through their viscosity, color, flavor and nutritional value. Four processing methods were selected for this study, including conventional hot break, waring blender with steam, steam injection, and high temperature with shear (HTS) in a twin-screw continuous processor. The HTS method applies high temperature with shear mixer during hot-break tomato processing that improves the efficiency of the extraction process and the resultant tomato products possessed higher consistency, viscosity, and lycopene content. Lycopene is an excellent antioxidant with cancer-preventing properties. This work showed that HTS method, utilizing whole tomatoes, produced a superior tomato product with a better color, higher viscosity, and improved bioactive properties.
\end{abstract}

\section{Keywords}

Tomato Processing, Pectin, Viscosity, Nutrients, Product Quality

\section{Introduction}

Tomatoes and tomato-based foods are an important part of the American diet and are found in a large variety of food products imparting both unique appetizing flavor and viscosity. Tomatoes have also been recognized as a source of carotenoids such as lycopene, a very important class of bioactive compounds especially known for their anti-inflammatory properties and supporting prostate health [1]. In United States, the production of tomato paste reached several million tons with an economic value of several billion dollars. Improving the quality 
of tomato products as well as reducing the production cost will benefit greatly the tomato growers, processors, and the consumers. The quality of the processed tomato product is dependent upon processing conditions. It is important for tomato processors to know how to obtain high viscosity products to prevent loss of flavor and nutritional quality by preventing loss and increase the bioavailability of lycopene and appropriate evaluation of the tomato products [2].

Tomato paste is commonly produced by the hot-break processing method: a rapid deactivation of pectolytic enzymes during the hot-break process is considered essential to prevent demethylation and break-down of pectin molecules [3] [4]. The consistency of the product also depends on the bio-availability of various compounds, such as pectin and other hydro-colloids (e.g., hemicelluloses). If the initial product is rich in these hydro-colloids, and subsequently evaporated to produce tomato paste, it results in a high consistency tomato paste [5].

Lycopene is a major pigment in tomatoes that is largely responsible for the red color, and it has also important health properties [5] [6]. Since tomatoes and related products are a major source of lycopene, it is very important to consider the source of carotenoids (lycopene) in the human diet [7]. As a natural source of antioxidant, lycopene can prevent epithelial cancers and improve heart health, preventing heart attacks and strokes [1]. The tomato skin contains $72 \%-92 \%$ of the lycopene that is found in the water insoluble fraction [8] and in conventional hot-break processing, the majority of the outer tissues are discarded as waste. Using the hot break method and subsequent evaporation process, lycopene pigment retains its bright red color and is stable [9].

Pectin and hemicelluloses (i.e., dietary fibers) are major polysaccharide components of plant cell walls, and the extraction efficiency of these substances depends on their solubility from the cell wall into the extract. One type of commercially available pectin forms a gel after thermal treatment at $95^{\circ} \mathrm{C}\left(203^{\circ} \mathrm{F}\right)$, followed by cooling [10]. The high temperature facilitates a dissociated, disordered pectin conformation that facilitates the extraction process [11]. Similarly, hemicelluloses respond to high temperature in the same manner [12]. The viscosities of these substances are very high due to their high molecular weight. The conventional hot-break extraction process is usually carried out at a temperature around $94^{\circ} \mathrm{C}-97^{\circ} \mathrm{C}$ [4], and the cold break processing temperature is $77^{\circ} \mathrm{C}$ or low. Hot break method results in a much more viscous product for using as ketchup, sauces, etc., whereas cold break method can produce better flavor and color retention product.

Pectin retention has been a key processing goal, in order to maintain high quality of the tomato paste during processing. It is impossible to retain $100 \%$ of pectic substances even under the best practical commercial conditions of rapid heating of crushed tomatoes; there is a time gap between the crushing and heating that is crucial in defining the degree of pectin degradation: a reduced time gap coincides with higher pectin retention and higher viscosity. Therefore, li- 
mited cellular destruction of tomatoes prior to hot breaking can reduce pectin degradation in the final products [13]. The objective of this study was to develop a novel processing technology to process whole tomatoes by a twin-screw continuous processor to provide high temperature with shear. This technology minimizes the time gap between crushing and hot breaking, maximizing pectin content, and optimizing the viscosity, resultant color, and shelf life of the tomato products.

\section{Experimental Procedures}

\subsection{Processing Methods, Separation and Concentration}

\subsubsection{Twin Screw Continuous Processor Methods (Steam Directly Injection and Steam in Jacket)}

The fresh industry tomatoes (roma) were obtained from Red Gold Inc. (Elwood, Indiana). In this process, each trial 20 pounds of whole tomatoes were fed into a twin-screw continuous processor (Readco Kurimoto, Ltd., York, PA, USA), in which the rotating speed and paddle configuration provide an optimal shear action to agitate and break down tomato particles. Process parameters included are rotating speed at $120 \mathrm{rpm}$, and the outlet temperature up to $100^{\circ} \mathrm{C}$ induced by adjusting pressure in the steam jacket. This was called high temperature with shear (HTS) processing. Another method that can be used is steam injection where steam was directly injected into the chamber of the processor.

\subsubsection{Hot-Break Processing Method}

Hot break of the tomato in the kettle simulates the conventional process method used in industry with some modification [14]. Whole tomatoes (20 pounds/each batch) were broken by the continuous processor without shear at room temperature and dropped into a kettle (Model DN/RA-15, Groen, Elkgrove Village, IL). The kettle was equipped with a steam jacket and variable speed agitator. The tomato product was maintained at $95^{\circ} \mathrm{C}$ in the kettle for two minutes, and then put through the finisher.

\subsubsection{Waring Blender Processing Method}

A Waring blender with a steam injection was set up to break tomatoes. The whole tomatoes ( 5 pounds/each trial) were added to a waring blender (Model \#34BL22, Dynamics Corporation of America, New Hartford, Connecticut) with steam injection, and processed for two minutes, followed by immediate passing through a finisher.

\subsubsection{Separation of Skins and Seeds from Processed Tomato Product}

The processed products were collected into 10-gallon 316 stainless steel containers and immediately put through the finisher (Model 150, Langsenkamp Manufacturer, and Indianapolis, IN), with 0.045 in screen opening, this removed the skin and seeds to get a clean tomato product. The consistency, serum viscosity, and precipitate weight ratio (PPT) of this product was measured immediately, and the product was then stored in a freezer $\left(20^{\circ} \mathrm{C}\right)$ for future analysis. 


\subsubsection{Production of Tomato Concentrate}

The processed tomato was concentrated in an open steam jacketed kettle. The consistency and viscosity were measured during the concentration at different Brix .

Evaporation was carried out using a kettle with scrape surface agitator and the steam jacket steam pressure was 100 psi. The vacuum was maintained at 15 inch of mercury $180^{\circ} \mathrm{F}$, and samples were taken until the soluble solids exceeded 24 Brix $^{\circ}$. The concentrated tomato product was canned and stored at room temperature for further physical and quality analysis.

\subsection{Determination of Consistency and Serum Viscosity}

\subsubsection{Determination of Consistency in Tomato Product}

The consistency or the gross viscosity of the tomato product was measured after the finisher, evaporation, and reconstitution of tomato suspensions using efflux pipette to determine their efflux viscosity for tomato product. This method was followed from Thakur and Singh [15], Crandall and Nelson [16]. Average values from triplicate measurements were reported.

\subsubsection{Determination of Serum Viscosity}

The viscosity of tomato sera were measured after separation by centrifugation. Each sample was centrifuged at $3000 \mathrm{rpm}$ for 15 minutes at $4^{\circ} \mathrm{C}$. The resulting supernatants were then transferred to an Oswald viscosity apparatus (\#100 and \# 200 hundred series) for serum viscosity analysis. The resultant precipitates (i.e., solids) were weighed, and the precipitate weight ratio (PPT) was calculated for each sample. This method was followed from Takada and Nelson [16], Barrett, et al. [12]. Average values from triplicate measurements were reported.

\subsection{Quality Analysis}

\subsubsection{The Total Tannic Content}

The total tannic content was determined by a modified Association of Official Analytical Chemists (AOAC) method. Concentrated tomato product (5 g) was diluted in $100 \mathrm{ml}$ of distilled water, and filtered. $5 \mathrm{ml}$ of this sample was mixed with $5 \mathrm{ml}$ indigo solution and then titrated using an aqueous solution of $\mathrm{KMnO}_{4}$ $(0.1 \mathrm{~N})$ until the color turned from green to golden-yellow. The results were compared with blank tests (blank tests $=$ titration of a mixture of $5 \mathrm{ml}$ indigo solution and $100 \mathrm{ml}$ distilled water) by titration [17] [18]. Each experiment was run in triplicate.

\subsubsection{Vitamin C Content}

Vitamin C content was analyzed by a modified method of Albrecht [19] and $\mathrm{Hu}$ [20]. The concentrated tomato sample $10 \mathrm{~g}$ in $50 \mathrm{ml}$ distilled water was titrated against 2,6-dichloroindophenol dye using a $2 \%$ oxalic acid as the extracting medium. The results were expressed as $\mathrm{mg} / 100 \mathrm{~g}$ fresh weight concentrate [21] [22]. Each experiment was run in triplicate. 


\subsubsection{Lycopene Content Analyses}

Lycopene content analyses were performed using a modified and simplified method from Bunghez et al. [21]. Concentrated tomato sample (0.3 g) was mixed with methanol, filtered, and then washed with a methanol rinse until the filtrate was colorless. The lycopene in the residue was extracted by adding small aliquots of hexane until the filtrate was colorless. The filtrate was then brought to $50 \mathrm{ml}$, and the solution was measured with a spectrophotometer (Model: UV2-100, UNICAM) at $485 \mathrm{~nm}$, and the absorbance was compared to a standard solution made of Sudan red \#1 pigment dissolved in ethanol ( $0.025 \mathrm{~g}$ of Sudan Red in 50 $\mathrm{ml}$ of ethanol). $0.26 \mathrm{ml}$ of standard solution diluted to $50 \mathrm{ml}$ in ethanol is equivalent to $0.5 \mu \mathrm{g} / \mathrm{ml}$ of lycopene [22]. Each experiment was run in triplicate.

\subsubsection{The Total Pectin Content Measurement}

The total pectin content of the solids was measured using a modified the carbazole method: The concentrated tomato sample $(5 \mathrm{~g})$ was treated in $95 \%$ ethanol in a boiling water $\left(100^{\circ} \mathrm{C}\right)$ bath for 30 minutes, then filtered to obtain a filter cake. An additional $40 \mathrm{ml}$ distilled water was added to the cake, water-soluble pectin was extracted by heating the slurry at $25^{\circ} \mathrm{C}$ for 30 minutes. The soluble fraction was brought up to $50 \mathrm{ml}$ after filtration and washing the insoluble fraction was hydrolyzed with $100 \mathrm{ml}$ of $0.5 \mathrm{M}$ sulfuric acid for one hour at $100^{\circ} \mathrm{C}$, and the sample was transferred to a volumetric flask, and the volume was brought to $100 \mathrm{ml}$.

To determine the pectin content in the prepared samples, one milliliter of pectin sample was placed in a $20 \mathrm{ml}$ test tube. Six milliliters of concentrated sulfuric was added to the test tube and heated in a boiling bath for 20 minutes. After cooling, $0.2 \mathrm{ml}$ of $0.15 \%$ carbazole solution $(0.15 \mathrm{~g}$ reagent grade carbazole was dissolved in $100 \mathrm{ml}$ of purified ethyl alcohol) was added to the sample, and it was left in the dark for 2 hours; the sample was then measured with a spectrophotometer at $530 \mathrm{~nm}$. The standard curve was prepared with galacturonic acid (Sigma). Results were expressed as g/kg fresh weight basis [23] [24] [25]. Each experiment was run in triplicate.

\section{Results and Discussions}

\subsection{Effect of Physical Properties on the Tomato Sera}

In order to replicate the conventional method for processing tomatoes, a stainless-steel kettle was used to provide the required heat with the minimum amount of kneading action. The Waring blender reduced the size of tomato pieces, but did not impart significant extensional or compressive deformation to the pieces (i.e. kneading action), which helped to extract polysaccharides or lycopene from the skin and seeds into the product. With direct steam injection, the temperature was maintained at $100^{\circ} \mathrm{C}$, but the concentration of tomato product was reduced by the steam condensation. Since the volume of the processor chamber was constant, condensation of steam increases the liquid volume, and the resident time 
in the processor was reduced by approximately $15 \%$. Also, the kneading effect in the processor was reduced due to less inter-particle friction within the diluted mixture. However, the twin-screw continuous processor provided a high temperature with shear (HTS) action on the skin during the hot breaking process.

High-temperature processing of tomatoes, such as a conventional hot-break process, has been shown to improve the quality of tomato juice and paste [26] [27] [28]; but mechanical crushing or high-pressure treatment of tomatoes usually happened pre- or post-heat treatment. There is a time-gap between crushing and heat treatment that may allow for pectolytic enzyme activities and/ or an increase the oxidation potential. Unlike crushing (chopping), the shear could make structural changes or induce interactions between tomato components, yielding products with different rheological behavior compared to the conventional method [13] [29].

The consistency and precipitate weight (PPT) ratio of the extracted tomato product are indications of the quality of the tomato sera. Table 1 showed the properties of the tomato sera extracted by different methods. The values of consistency were 8.5 seconds and serum viscosity was $4.06 \mathrm{cps}$ in HTS method. This was 3.8 times and 2 times higher respectively than that produced by kettle method (the simulated hot-break method). Because the kettle method lacked the kneading action during the hot break, the release of molecules from the skin and seeds into the serum fraction was very slow and inefficient. There are potentially extractable polysaccharides remaining in the residual skin. Comparing with other two methods, the steam injection method yielded higher values in serum viscosity and similar PPT ratios with Waring blender method. This higher serum viscosity also indicated that the kneading action utilized in the processor mobilized pectin and other hydrocolloid compounds more efficiently. The consistency of the freshly extracted sera produced by the Waring blender method was slightly higher than the steam injection method. This might be due to the existence of small pieces of tomato skin in the sera produced by the chopping action of the blades that passed through the screen of the finisher.

Both the steam directly injection and steam in jacket around of processing chamber (HTS) methods had a kneading action, and the serum viscosities were

Table 1. Brix $^{\circ}$ and Consistency of tomato sera extracted by different processing methods, and Serum Viscosity and Precipitate Weight Ratio (PPT) after centrifugation.

\begin{tabular}{ccccc}
\hline Processing method & Brix $^{\circ}$ & Consistency (seconds) & Serum viscosity (cps) & PPT ratio \\
\hline $\begin{array}{c}\text { Kettle at } 95^{\circ} \mathrm{C} \\
\text { Waring Blender }\end{array}$ & 4.42 & $2.2 \pm 0.2$ & $1.94 \pm 0.04$ & $0.14 \pm 0.05$ \\
$\begin{array}{c}\text { with steam } \\
\text { Processor Steam } \\
\text { injection }\end{array}$ & 4.37 & $7 \pm 0.05$ & $2.1 \pm 0.01$ & $0.19 \pm 0.01$ \\
HTS & 4.71 & $5.5 \pm 0.5$ & $3.39 \pm 0.3$ & $0.2 \pm 0.01$ \\
\hline
\end{tabular}

The values of each data were normalized to equivalent of $4.42 \mathrm{Brix}^{\circ}$ assuming a linear relationship with Brix ${ }^{\circ}$ value. 
similar, but higher than either the Waring blender or Kettle methods (Figure 1). The serum viscosity of tomato sera reconstituted from concentrated tomato is shown in Figure 2. The shape of the curves for sera obtained by the either steam injection or HTS method was not a linear relationship and differed from the sera obtained by kettle or Waring blender methods. Takeda and Nelson [16] reported that the tomato paste was produced by hot-break with a kneading action, the relationships between consistency, serum viscosity, and PPT ratio would be different from those produced by traditional process methods.

\subsection{Effect of Processing Methods on the Quality of Tomato Concentrate Quality}

The quality of the concentrated tomato product was measured for the tannin

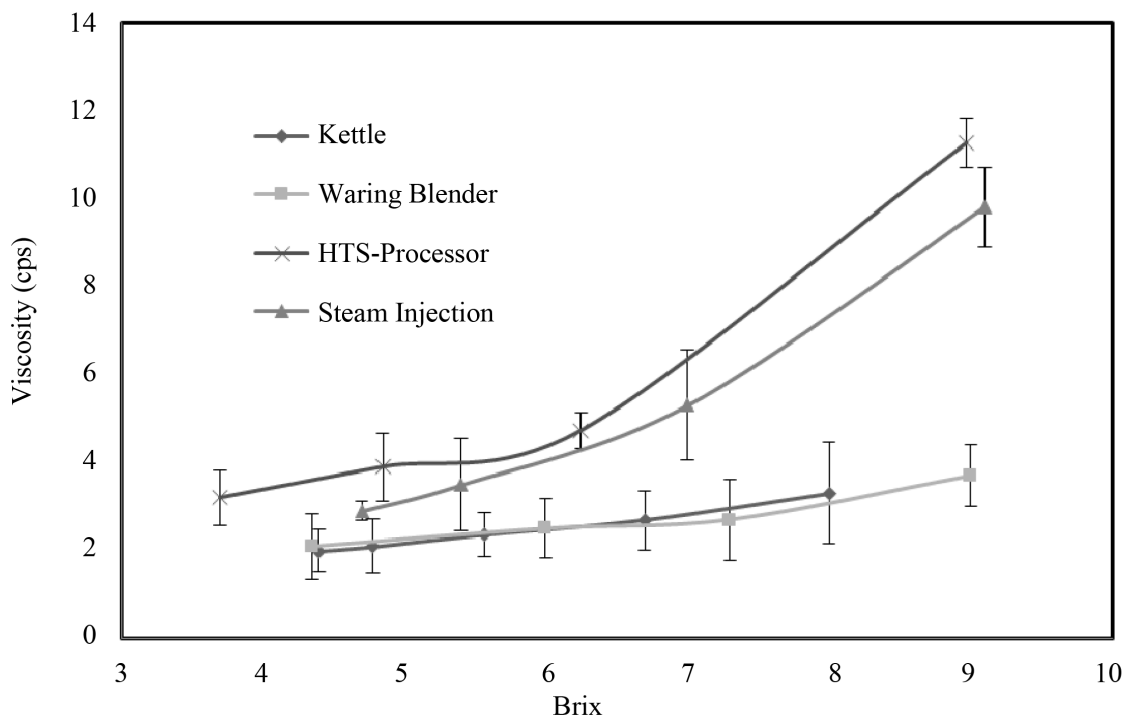

Figure 1. Effect of the processing methods on the Serum Viscosity of tomato sera during the evaporation.

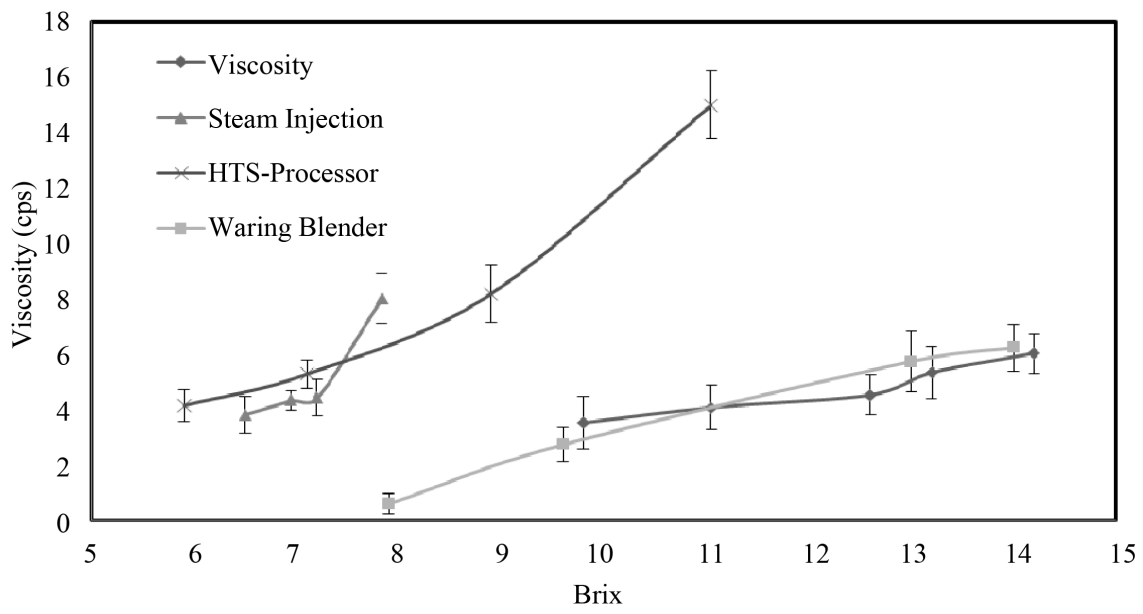

Figure 2. Effect of the processing methods on the Serum Viscosity of reconstituted tomato suspensions from tomato product after concentration. 
content, vitamin C content, lycopene content, and for total pectin extracted. The best quality of resultant products was for HTS method. The data in Table 2 showed that the tannin contents in Waring blender and HTS methods were lower than other two methods. The Waring blending method had the lowest vitamin C content, because the exposure of product to the air by blending action induced oxidation [13] [30]. The lowest lycopene content resulted from the steam injection method, which might cause larger water condensation with less kneading force lessening the extraction efficiency of lycopene from the tomato skin and seeds. In contrast, the total extracted pectin of twin-screw processor at $95^{\circ} \mathrm{C}$ was the lowest since the processing temperature was the lowest; following by processing in the Waring blender, which did rupture cell walls to improve the extraction efficiency of pectin and lycopene. However, the shear force in HTS method could break down cell walls for weakening the bonding forces between lycopene and tomato tissue matrix to increase the extraction of lycopene [7]. These series of experiments indicated that the application of high temperature, short time with shear (kneading action) facilitates the production of a highquality tomato product. In addition, when using HTS to process tomatoes, the resultant physical, chemical, and/or product behavior all change in both the serum and pulp, compared to those obtained by high temperature only, or high pressure at $25^{\circ} \mathrm{C}$, or other processing methods [31] [32]. Furthermore, HTS method provided high temperature and mechanical shear resulting in molecular transformation and chemical reaction [33].

\subsection{Effect of Total Soluble Solid (TSS) Content on the Loss of Consistency in Reconstituted Tomato Suspensions}

Tomato concentrate is manufactured by vacuum evaporation of tomato product to $24^{\circ}$ Brix (\% TSS), or above. Some studies suggested that the Bostwick value decreased logarithmically with the degree of paste concentration [34] [35]. During evaporation of the tomato sera to a concentration corresponding to $15^{\circ}$ Brix, the observed consistencies of the sera were found to be increased for all of four

Table 2. Qualities of tomato product after concentration from different processing methods.

\begin{tabular}{ccccc}
\hline Quality Item/Processing Methods & Processor $95^{\circ} \mathrm{C}$ & Waring blender with steam Processor Steam Injection & Processor HTS \\
\hline Water Soluble at $25^{\circ} \mathrm{C}\left(\right.$ Brix $\left.^{\circ}\right)$ & 25.8 & 25.39 & 24.92 & 21.6 \\
Water (\%) & $75.6 \pm 0.25$ & $76.6 \pm 0.05$ & $74.80 \pm 0.3$ & $78.4 \pm 0.05$ \\
Tannin (\%) & $4.18 \times 10^{-2} \pm 0.0$ & $3.73 \times 10^{-2} \pm 0.00$ & $4.43 \times 10^{-2} \pm 0.00$ & $3.69 \times 10^{-2} \pm 0.00$ \\
Vitamin $\mathrm{C}, \mathrm{mg} / 100 \mathrm{~g}$ & $44.6 \pm 0.05$ & $11.5 \pm 0.0$ & $38.10 \pm 0.0$ & $55.9 \pm 0.05$ \\
Lycopene, $\mathrm{mg} / 100 \mathrm{~g}$ & $29.7 \pm 0.11$ & $32.19 \pm 0.03$ & $20.99 \pm 0.00$ & $32.28 \pm 0.00$ \\
Pectin extracted at $25^{\circ} \mathrm{C}, \mathrm{g} / \mathrm{kg}$ & $17.78 \pm 0.32$ & $14.95 \pm 0.07$ & $15.64 \pm 0.02$ & $18.9 \pm 0.52$ \\
Pectin extracted at $100^{\circ} \mathrm{C}, \mathrm{g} / \mathrm{kg}$ & $14.36 \pm 0.41$ & $20.32 \pm 0.48$ & $18.35 \pm 0.47$ & $22.1 \pm 0.31$ \\
Total extracted pectin, $\mathrm{g} / \mathrm{kg}$ & 32.14 & 35.27 & 33.99 & 41.0 \\
\hline
\end{tabular}


processing methods, with the shear processor resulting in the highest consistency (Figure 3). The reconstituted tomato suspensions did not return to the original consistency or viscosity. As the concentration increased, the consistency of the reconstituted tomato suspension from concentrate continually decreased (Figure 4). The resulting finished product often loses as much as $40 \%$ of its original consistency [35] [36]. This means that when concentrated tomato was diluted to its original concentration, the consistency of the reconstituted suspensions had only approximately $30 \%$ to $40 \%$ of its original value [33] [36].

It is possible that the dissolved polymers reach a saturation point at approximately $15 \mathrm{Brix}^{\circ}$. Above this concentration, they slowly precipitated and dropped out of the serum resulting in more loss of consistency in the reconstituted

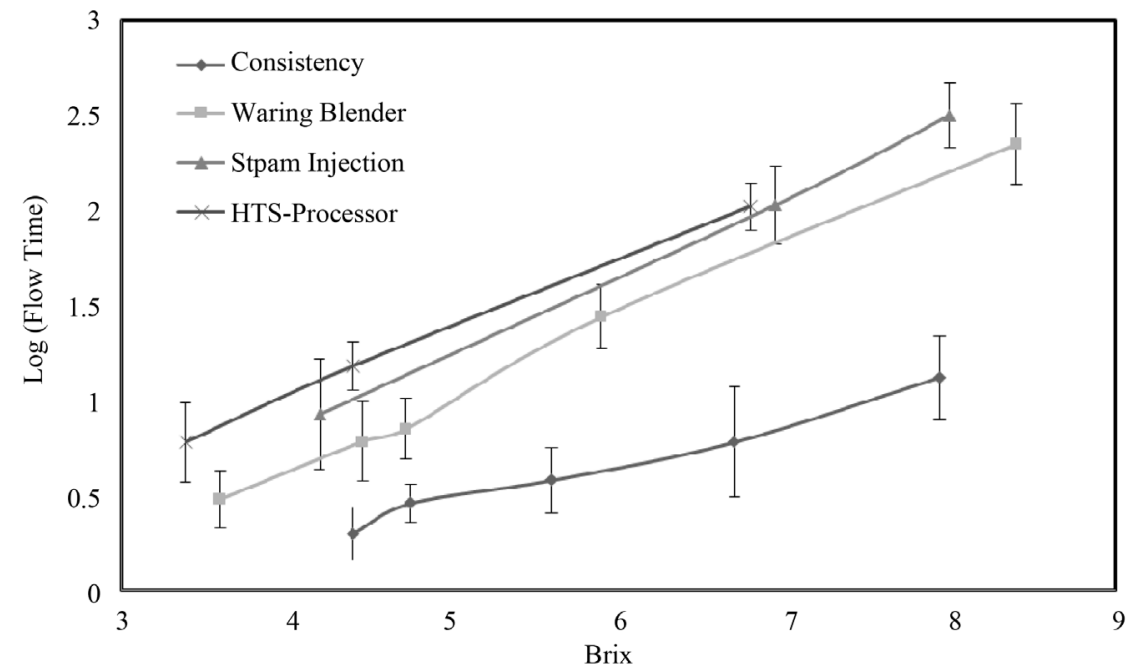

Figure 3. Effect of processing methods on the consistency of tomato sera during the evaporation.

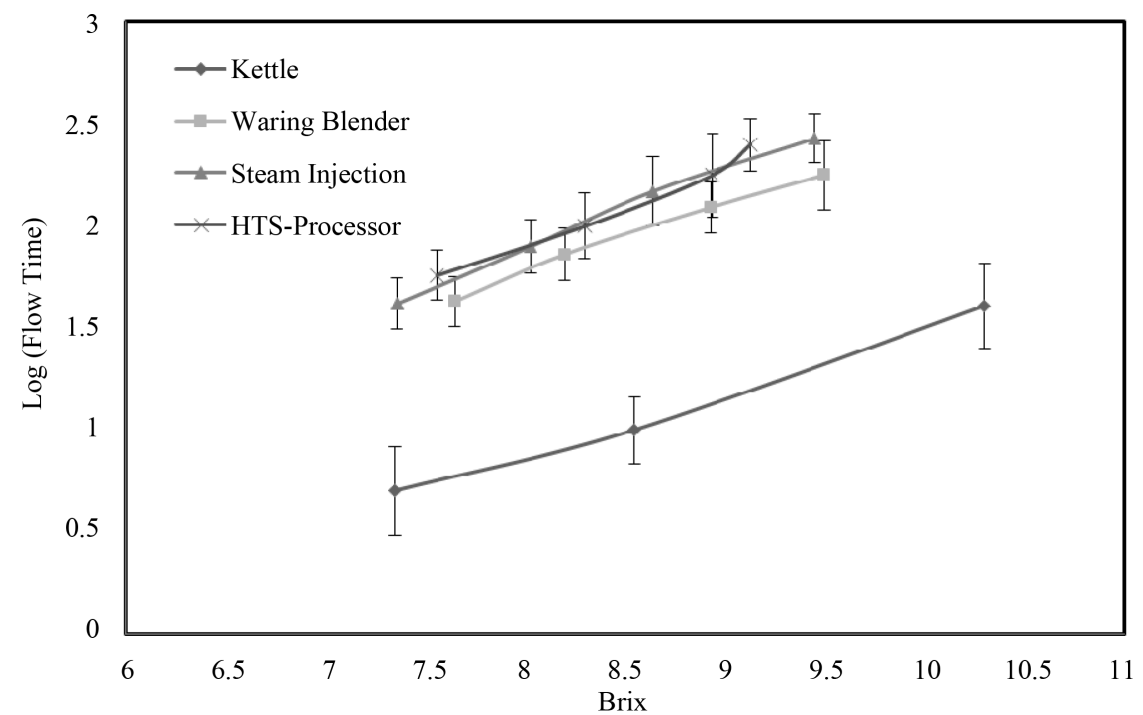

Figure 4. Effect of the processing methods on the consistency of reconstituted tomato suspensions from the tomato product after concentration. 
suspensions. In addition, when the temperature dropped, the solubility of the pectin or the other polymers decreased and they re-crystallized. Once crystallized, it was very difficult to be reconstituted [12] [37]. In other word, crystallization of these polymers was a slow process. A further drop of the consistency in the reconstituted tomato suspensions was observed after one week of storage. Compared to the original hot-break tomato paste, the consistency in the reconstituted juice dropped 2.2 fold upon production. It dropped additional 2.6 fold post storage at 35 days. However, this loss in consistency could be prevented when the reconstituted paste was heated to $90^{\circ} \mathrm{C}$ or above that can recovery of initial Bostwick and serum viscosity on the day of pack [33] [34] [35].

\section{Conclusions}

In contrast to the conventional hot-break method currently utilized in the tomato industry, this study induced a new tomato processing method using a twin-screw continuous processor that provides both high temperature and shear. This method facilitates the extraction of compounds from the tomato skin. The consistency and viscosity of the resultant tomato product was higher than the Kettle method, which was analogous to the industry hot break. Consistency of the tomato suspension from tomato concentrate was dependent on the processing methods used. This research has shown a novel processing technology, which yields a tomato product with high quality, better nutrient value, and longer shelf life.

Future research will include optimization of the processing parameters and the secondary utilization of tomato skin and seeds for further processing, such as grinding them into a fine powder for addition into tomato products for increased consistency and nutritional value.

\section{Acknowledgements}

We thank Red Gold Inc. (Elwood, IN) which provided tomatoes for this project, and Drs. Tahira Fatima and Shusheng Wang for critical review of the manuscript. Financial support is from the John \& Emma Tse through Li-Fu Chen memorial Laboratory fund and Whistler Center for Carbohydrate Research.

\section{References}

[1] Singh, P. and Goyal, G.K. (2008) Dietary Lycopene: Its Properties and Anticarcinogenic Effects. Comprehensive Reviews in Food Science and Food Safety, 7, 255-270. https://doi.org/10.1111/j.1541-4337.2008.00044.x

[2] Preedy, V.R. and Watson, R.R. (Eds.) (2008) Tomatoes and Tomato Products: Nutritional, Medicinal and Therapeutic Properties. Science Publishers, Enfield, NH. https://doi.org/10.1201/9781439843390

[3] Gould, W. and Gould (1992) Tomato Production, Processing and Technology. Elsevier, Inc., Woodhead Publishing, Cambridge, UK. https://doi.org/10.1533/9781845696146

[4] Luh, B.S., Dempsey, W.H. and Leonard, S. (1954) Consistency of Pastes and Purees 
from Pearson and San Marzano Tomatoes. Food Technology, 8, 576.

[5] Zuorro, A. and Lavecchia, R. (2010) Mild Enzymatic Method for the Extraction of Lycopene from Tomato Paste. Biotechnology \& Biotechnological Equipment, 24, 1854-1857. https://doi.org/10.2478/V10133-010-0028-0

[6] Mirondo, R. and Barringer, S. (2015) Improvement of Flavor and Viscosity in Hot and Cold Break Tomato Juice and Sauce by Peel Removal. Journal of Food Science, 80, S171-S179. https://doi.org/10.1111/1750-3841.12725

[7] Shi, J. and Le Maguer, M. (2001) Degradation of Lycopene in Tomato Process. Acta Horticulturae, 542, 289-296. https://doi.org/10.17660/ActaHortic.2001.542.38

[8] Rozzi, N.L., Singh, R.K., Vierling, R.A. and Watkins, B.A. (2002) Supercritical Fluid Extraction of Lycopene from Tomato Processing Byproducts. Journal of Agricultural and Food Chemistry, 50, 2638-2643. https://doi.org/10.1021/jf011001t

[9] Takeoka, G.R., Dao, L., Flessa, S., Gillespie, D.M., Jewell, W.T., Huebner, B. and Ebeler, S.E. (2001) Processing Effects on Lycopene Content and Antioxidant Activity of Tomatoes. Journal of Agricultural and Food Chemistry, 49, 3713-3717. https://doi.org/10.1021/jf0102721

[10] Thakur, B.R., Singh, R.K., Handa, A.K. and Rao, M.A. (1997) Chemistry and Uses of Pectin-A Review. Critical Reviews in Food Science and Nutrition, 37, 47-73. https://doi.org/10.1080/10408399709527767

[11] Diaz, J.V., Anthon, G.E. and Barrett, D.M. (2009) Conformational Changes in Serum Pectins during Industrial Tomato Paste Production. Journal of Agricultural and Food Chemistry, 57, 8453-8458. https://doi.org/10.1021/jf901207w

[12] Barrett, D.M., Garcia, E. and Wayne, J.E. (1998) Textural Modification of Processing Tomatoes. Critical Reviews in Food Science and Nutrition, 38, 173-258. https://doi.org/10.1080/10408699891274192

[13] Kaur, C., George, B., Deepa, N., Jaggi, S. and Kapoor, H.C. (2007) Viscosity and Quality of Tomato Juice as Affected by Processing Methods. Journal of Food Quality, 30, 864-877. https://doi.org/10.1111/j.1745-4557.2007.00166.x

[14] Crandall, P.G. and Nelson, P.E. (1975) Effects of Preparation and Milling on Consistenty of Tomato Juice and Puree. Journal of Food Science, 40, 710-713. https://doi.org/10.1111/j.1365-2621.1975.tb00537.x

[15] Thakur, B.R., Singh, R.K. and Handa, A.K. (1995) Effect of Homogenization Pressure on Consistency of Tomato Juice. Journal of Food Quality, 18, 389-396. https://doi.org/10.1111/j.1745-4557.1995.tb00389.x

[16] Takada, N. and Nelson, P.E. (1983) Pectin-Protein Interaction in Tomato Products. Journal of Food Science, 48, 1408-1411. https://doi.org/10.1111/j.1365-2621.1983.tb03503.x

[17] Atanassova, M. and Christova-Bagdassarian, V. (2009) Determination of Tannins Content by Titrimetric Method for Comparison of Different Plant Species. Journal of the University of Chemical Technology and Metallurgy, 44, 413-415.

[18] Sulaiman (2013) Phenolic Content, Antioxidant, Antimicrobial and Cytotoxic Activities of Ethanolic Extract of Salix Alba. American Journal of Biochemistry and Biotechnology, 9, 41-46. https://doi.org/10.3844/ajbbsp.2013.41.46

[19] Albrecht, J.A., Schafer, H.W. and Zottola, E.A. (1990) Relationship of Total Sulfur to Initial and Retained Ascorbic Acid in Selected Cruciferous and Noncruciferous Vegetables. Journal of Food Science, 55, 181-183. https://doi.org/10.1111/j.1365-2621.1990.tb06047.x

[20] Hu, L., Li, L., Luo, Z., Yang, J. and Liu, W. (2012) Determination of Trace Vitamin 
C by Ion-Pair HPLC with UV Detection in Calcium Gluconate and Vitamin C Compound Oral Solution. Journal of Chromatographic Science, 50, 102-107. https://doi.org/10.1093/chromsci/bmr035

[21] Bunghez, R., Raduly, M., Doncea, S., Aksahin, I. and Ion, R.-M. (2011) Lycopene Determination in Tomatoes by Different Spectral Techniques (UV-VIS, FTIR and HPLC). Digest Journal of Nanomaterials and Biostructures, 6, 1349-1356.

[22] Fish, W.W., Perkins-Veazie, P. and Collins, J.K. (2002) A Quantitative Assay for Lycopene That Utilizes Reduced Volumes of Organic Solvents. Journal of Food Composition and Analysis, 15, 309-317. https://doi.org/10.1006/jfca.2002.1069

[23] Dische, Z. (1947) A New Specific Color Reaction of Hexuronic Acids. The Journal of Biological Chemistry, 167, 189-198.

[24] McComb, E.A. and McCready, R.M. (1952) Colorimetric Determination of Pectic Substances. Journal of Analytical Chemistry, 24, 1630-1632. https://doi.org/10.1021/ac60070a036

[25] Doner, L.W. (1986) Analytical Methods for Determining Pectin Composition. In: Fishman, M.L. and Jen, J.J., Eds., Chemistry and Function of Pectins, American Chemical Society, Washington DC, Vol. 310, 13-21.

[26] Kubo, M.T.K., Augusto, P.E.D. and Cristianini, M. (2013) Effect of High Pressure Homogenization (HPH) on the Physical Stability of Tomato Juice. Food Research International, 51, 170-179. https://doi.org/10.1016/j.foodres.2012.12.004

[27] Boulekou, S.S., Stoforos, N.G., Katsaros, G.J., Taoukis, P.S. and Mallidis, K. (2007) Effect of High Pressure on Quality Parameters of Cherry Tomato Juice. Acta Horticulturae, 758, 139-144. https://doi.org/10.17660/ActaHortic.2007.758.14

[28] Heidarinasab, A. and Moghaddam Nansa, V. (2010) Time Independent Behavior of Tomato Paste. International Journal of Nutrition and Food Engineering, 4, 142-145.

[29] Saranya, R., Devanesan, G., Ramesh, S. and Gopi, R. (2017) Effect of Processing on Nutritional Quality and Antioxidant Potentials of Leafy Vegetables. Journal of Food Processing \& Technology, 8, 694.

[30] Luh, B. and Daoud, H.N. (1971) Effect of Break Temperature and Holding Time on Pectin and Pectic Enzymes in Tomato Pulp. Journal of Food Science, 36, 1039-1043. https://doi.org/10.1111/j.1365-2621.1971.tb03341.x

[31] Christiaens, S., Uwibambe, D., Uyttebroek, M., Van Droogenbroeck, B., Van Loey, A.M. and Hendrickx, M.E. (2015) Pectin Characterisation in Vegetable Waste Streams: A Starting Point for Waste Valorisation in the Food Industry. LWT-Food Science and Technology, 61, 275-282. https://doi.org/10.1016/j.lwt.2014.12.054

[32] Luterotti, S., Bicanic, D., Markovic, K. and Franko, M. (2015) Carotenes in Processed Tomato after Thermal Treatment. Food Control, 48, 67-74. https://doi.org/10.1016/j.foodcont.2014.06.004

[33] Anthon, G.E. and Barrett, D.M. (2010) Changes in Tomato Paste During Storage and Effects of Heating on Consistency of Reconstituted Tomato Paste: Consistency Changes during Tomato Paste Storage. Journal of Texture Studies, 41, 262-278. https://doi.org/10.1111/j.1745-4603.2010.00225.x

[34] Marsh, G.L., Buhlert, J.E. and Leonard, S.J. (1980) Effect of Composition upon Bostwick Consistency of Tomato Concentrate. Journal of Food Science, 45, 703-710.

[35] Anthon, G.E., Diaz, J.V. and Barrett, D.M. (2008) Changes in Pectins and Product Consistency during the Concentration of Tomato Juice to Paste. Journal of Agricultural and Food Chemistry, 56, 7100-7105. https://doi.org/10.1021/jf8008525

[36] Tanglertpaibul, T. and Rao, M.A. (1987) Rheological Properties of Tomato Concen- 
trates as Affected by Particle Size and Methods of Concentration. Journal of Food Science, 52, 141-145. https://doi.org/10.1111/j.1365-2621.1987.tb13991.x

[37] Sherkat, F. and Luh, B.S. (1976) Quality Factors of Tomato Pastes Made at Several Break Temperatures. Journal of Agricultural and Food Chemistry, 24, 1155-1158. https://doi.org/10.1021/jf60208a032 